\title{
Role of the Septum in the Excitatory Effect of Corticotropin- Releasing Hormone on the Acoustic Startle Reflex
}

\author{
Younglim Lee and Michael Davis \\ Department of Psychiatry, Yale University, New Haven, Connecticut 06508
}

\begin{abstract}
Intracerebroventricular administration of corticotropin-releasing hormone $(\mathrm{CRH})$ elicits a constellation of behavioral, autonomic, and endocrinological changes typically observed in stress. One of the behavioral changes after intracerebroventricular $\mathrm{CRH}$ is a profound increase of startle amplitude ( $\mathrm{CRH}$-enhanced startle). The present study examined the role of the septum in $\mathrm{CRH}$ enhanced startle. The septum has direct and indirect connections to the amygdala and inhibits the amygdala. Electrophysiological data show that $\mathrm{CRH}$ in the septum is inhibitory. Therefore, it has been hypothesized that intracerebroventricular $\mathrm{CRH}$ inhibits the septum, which in turn disinhibits the amygdala, resulting in a constellation of changes via activation of amygdala efferent targets. In testing this hypothesis, it was found that electrolytic lesions of the medial septum, but not the lateral septum, blocked $\mathrm{CRH}$-enhanced startle. However, fiber-
\end{abstract}

sparing chemical lesions of the medial septum did not block $\mathrm{CRH}$-enhanced startle, suggesting that the blockade seen with the electrolytic lesions was caused by damage to fibers of passage. A major fiber bundle passing through the medial septum is the fornix, the primary efferent pathway for the hippocampus. Fimbria transection blocked $\mathrm{CRH}$-enhanced startle almost completely, whereas the large electrolytic lesions of the dorsal hippocampus did not block $\mathrm{CRH}$-enhanced startle. Taken together, these data suggest that perhaps the ventral hippocampus and its efferent target areas, which communicate via the fimbria, may be critically involved in $\mathrm{CRH}$-enhanced startle.

Key words: septum; fimbria; hippocampus; corticotropinreleasing hormone $(\mathrm{CRH})$; startle; stress
The goal of the following series of experiments was to delineate some of the neural substrates involved in laboratory models of stress and anxiety to obtain a better understanding of the pathophysiology underlying stress-induced affective disorders. One of the animal models used in stress research involves intracerebroventricular infusion of corticotropin-releasing hormone ( $\mathrm{CRH})$. Thus, intracerebroventricular infusion of CRH elicits a constellation of behavioral, physiological, and endocrinological changes normally observed after stress (cf. Dunn and Berridge, 1990). Interestingly, some of these changes are similar to symptoms seen in certain psychiatric disorders, such as post-traumatic stress disorder (PTSD). For example, infusion of CRH causes a profound, dose-related increase in the acoustic startle response (CRH-enhanced startle) (Swerdlow et al., 1986; Liang et al., 1992a). Similarly, patients with PTSD have elevated CSF levels of CRH (Darnell et al., 1994) and show increased startle responses under appropriate test conditions (Morgan et al., 1995). In fact, increased startle is one of the diagnostic criteria for PTSD according to the Diagnostic and Statistical Manual of Mental Disorders (fourth edition; American Psychiatric Association).

Although the cause of the elevated CSF CRH levels in these patients is not known, it is important to ask whether elevated levels of CSF CRH can interact with brain structures to manifest some of the symptoms seen in this disorder. In this regard, the acoustic startle reflex seems to be an excellent model system to

Received Jan. 13, 1997; revised May 21, 1997; accepted May 29, 1997.

This research was supported by National Institute of Mental Health Grant MH-47840, Research Scientist Development Award MH-00004 to M.D., a grant from the Air Force Office of Scientific Research, and the state of Connecticut.

Correspondence should be addressed to Dr. Michael Davis, Yale University, Department of Psychiatry, Connecticut Mental Health Center, 34 Park Street, New Haven, CT 06508.

Copyright (C) 1997 Society for Neuroscience $\quad 0270-6474 / 97 / 176424-10 \$ 05.00 / 0$ investigate the effects of $\mathrm{CRH}$ on the CNS. The acoustic startle reflex is a short-latency response of the skeletal musculature elicited by a sudden auditory stimulus (cf. Davis, 1984), and a primary neural pathway mediating this response has been delineated (Davis et al., 1982; Lingenhöhl and Friauf, 1994; Yeomans and Frankland, 1995; Lee et al., 1996). The acoustic startle reflex also can be modulated by stress, fear, or other negative affective states (cf. Davis, 1988).

Using lesion and microinf usion techniques, previous work from our laboratory and others showed that $\mathrm{CRH}$-enhanced startle is blocked by both intracerebroventricular infusion of a CRH antagonist, $\alpha$-helical $\mathrm{CRH}_{9-41}$ (Swerdlow et al., 1989; Liang et al., 1992a) and electrolytic lesions of the amygdala (Liang et al., 1992b). However, intra-amygdala infusion of $\mathrm{CRH}$ failed to mimic the intracerebroventricular CRH effect on startle, suggesting that the amygdala may be a critical part of the neuronal circuitry necessary for the expression of CRH-enhanced startle, but that the primary receptor site is located in some other structure(s) efferent to the amygdala (Liang et al., 1992b).

The septum might be a primary receptor site for intracerebroventricular $\mathrm{CRH}$ for a number of reasons. First, the septum is close to the lateral ventricle, and both the lateral and medial septum contain a moderate to dense number of CRH receptors (De Souza et al., 1984; Chalmers et al., 1995). Second, studies of immediate early gene activation have shown that various limbic structures, including the lateral septum, are activated by intracerebroventricular CRH (Arnold et al., 1992; Imaki et al., 1993). Third, the septum shows strong connections to areas implicated in stress responses, such as the paraventricular nucleus of the hypothalamus, the dorsal raphe nucleus, and the locus coeruleus (Swanson and Cowan, 1979; Silverman et al., 1981; Sawchenko and Swanson, 1983; Moga et al., 1991; Staiger and Nürnberger, 
1991). The medial septum has a direct projection to the amygdala, whereas the lateral septum has both a direct projection and a more extensive indirect projection to the amygdala (Meibach and Siegel, 1977; Russchen, 1982; Dudley et al., 1990; Volz et al., 1990; Staiger and Nürnberger, 1991).

Although controversial, it has been suggested that the septum and the amygdala may play opposite roles in fear and anxiety responses. For example, using startle responses, Miller and Treft (1979), as well as Lee et al. (1988), demonstrated that animals with lateral septum lesions showed increased startle amplitudes to auditory and air puff stimuli, perhaps indicative of increased fear. Studies from our laboratory confirmed and extended this finding. Melia et al. (1991) reported that acoustic startle is facilitated by whole septal lesions but not by amygdala lesions. However, concomitant lesions of the amygdala and septal area blocked the excitatory effect on startle normally observed after septal lesions alone (Melia et al., 1991). Others also reported that lesions of the amygdala blocked hyperemotionality produced by whole septal lesions (King and Meyer, 1958; Schwartzbaum and Gray, 1966; Kleiner et al., 1967). Taken together, these functional, anatomical studies suggest that the septum may normally dampen, or inhibit the amygdala, so that the anxiogenic effects induced by septal lesions result from a disinhibition of the amygdala.

Thus, the septum seems to be an interesting candidate as a primary site where CRH binds and elevates the startle reflex after intracerebroventricular infusion. It is known that iontophoretic application of $\mathrm{CRH}$ into the lateral septum inhibits neuronal activity in this area (Eberly et al., 1983). Therefore, given the fact that the septum may tonically inhibit the amygdala (see above), one can hypothesize that intracerebroventricular CRH elevates startle via inhibition of septal function, leading to a disinhibition of the amygdala. This would explain why intracerebroventricular $\mathrm{CRH}$ produces a constellation of behaviors similar to electrical stimulation of the amygdala (cf. Dunn and Berridge, 1990).

To conclude that a brain structure serves as a primary receptor site for mediating effects of a certain compound after intracerebroventricular administration, the following three criteria must be met: (1) lesions of the structure should block the effects of the compound; (2) direct infusion of the compound into the brain area should mimic the effects of the compound given intracerebroventricularly; and (3) an antagonist of the compound infused into the brain structure should block the effects of the compound given intracerebroventricularly. Using these criteria, the following experiments were designed to examine the role of the septum in mediating $\mathrm{CRH}$-enhanced startle.

\section{MATERIALS AND METHODS}

\section{Animals}

Male Sprague Dawley rats (Charles River, Kingston, NY) weighing $350-430 \mathrm{gm}$ were used. The animals were housed in groups of three before surgery in $20 \times 24 \times 36 \mathrm{~cm}$ hanging wire cages and were housed singly in $19 \times 20 \times 25 \mathrm{~cm}$ hanging wire cages after surgery. The animal colony was on a $12 \mathrm{hr}$ light/dark schedule (lights on at 7 A.M.) with food and water continuously available.

\section{Startle apparatus}

Five separate stabilimeters were used to record the amplitude of the startle response. Each stabilimeter consisted of an $8 \times 15 \times 15 \mathrm{~cm}$ Plexiglas and wire mesh cage suspended between compression springs within a steel frame. Cage movement resulted in displacement of an accelerometer, in which the resultant voltage was proportional to the velocity of cage displacement. The analog output of the accelerometer was amplified and digitized on a scale of $0-4096$ units by a MacADIOS II board (GW Instruments, Somerville, MA) interfaced to an Apple
Macintosh II microcomputer. Startle amplitude was defined as the peak accelerometer voltage that occurred during the first $200 \mathrm{msec}$ after onset of the startle stimulus. The stabilimeters were housed in a ventilated, dark, sound-attenuating chamber $(2.5 \times 2.5 \times 2 \mathrm{~m}$; Industrial Acoustic Co. $)$.

The startle stimuli were delivered by high-frequency Radio Shack super tweeters (range, $5-40 \mathrm{kHz}$ ) located $10 \mathrm{~cm}$ behind each stabilimeter. Startle stimuli were $50 \mathrm{msec}$ bursts of white noise, generated by a Lafayette 15800 noise generator $(0-20 \mathrm{kHz})$, with a rise-decay time of $5 \mathrm{msec}$ at an intensity of $105 \mathrm{~dB}$. Throughout all experiments, background white noise $(0-20 \mathrm{kHz})$ of $55 \mathrm{~dB}$ sound pressure level was provided by a white noise generator (Lafayette 15800) and delivered by a single Jamocar 70 speaker (range, $0.02-20 \mathrm{kHz}$ ), located $\sim 70 \mathrm{~cm}$ in front of each cage. Sound level measurements were made with a Brüel \& Kjær (Marlborough, MA) 4133 condenser microphone fitted to a Brüel \& Kjær 2235 sound level meter (A scale, random input).

Presurgery matching. Three weeks after delivery, the animals were placed in the startle test cages and given a presurgery matching test. After a 5 min acclimation period, the animals were presented with 60 startle-eliciting noise bursts at $105 \mathrm{~dB}$. The intertrial interval (ITI) was $30 \mathrm{sec}$. The animals were subsequently divided into sham or lesion groups, having similar mean startle amplitudes across the last 10 startle stimuli. This block of time was chosen because startle amplitudes generally habituate to a reasonably stable level after $40-50$ startle stimuli using these parameters.

\section{Surgery}

Electrolytic lesions of the septum. Rats were anesthetized with Nembutal $(50 \mathrm{mg} / \mathrm{kg}$, i.p.) and placed in a Kopf 900 stereotaxic instrument with blunt ear bars. The skin was retracted, and bilateral holes were drilled in the skull above the structures to be lesioned. An NE-300 electrode ( 0.25 $\mathrm{mm}$ diameter, insulated to within $0.5 \mathrm{~mm}$ of the tip; Rhodes Medical Instrument) was lowered into the brain, and a lesion was made by passing a 0.1-2 mA DC current (anode in the brain) for 10-40 sec. The lesion parameters and coordinates for each area with respect to bregma were as follows: whole septum $(n=15,2 \mathrm{~mA}$ current for $30 \mathrm{sec}),+0.6 \mathrm{~mm}$ anteroposterior (AP), $\pm 0.5 \mathrm{~mm}$ mediolateral (ML), and $-6.5 \mathrm{~mm}$ dorsoventral (DV); medial septum $(n=20,2 \mathrm{~mA}$ current for $10 \mathrm{sec}),+0.6$ $\mathrm{mm} \mathrm{AP,} 0.0 \mathrm{~mm} \mathrm{ML}$, and $-6.8 \mathrm{~mm} \mathrm{DV}$; and lateral septum $(n=20,0.1$ $\mathrm{mA}$ for $40 \mathrm{sec}$ ), first drop, $+1.2 \mathrm{~mm} \mathrm{AP}, \pm 0.7 \mathrm{~mm} \mathrm{ML}$, and $-5.0 \mathrm{~mm}$ $\mathrm{DV}$; second drop, $+0.2 \mathrm{~mm}$ AP, $\pm 1.1 \mathrm{~mm} \mathrm{ML}$, and $-4.7 \mathrm{~mm} \mathrm{DV}$. The procedure for the sham lesion $(n=10)$ was identical, except that no current was delivered. The coordinates for the sham lesion were same as those of the whole septum lesion.

Kainic acid and NMDA lesions of the medial septum. A pilot study showed that in the medial septum, the types of cells lesioned by either kainic acid or NMDA seemed to be slightly different. Therefore, both

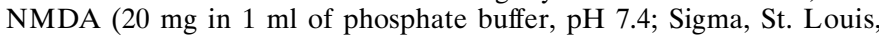
MO) and kainic acid (6.4 mg in $1 \mathrm{ml}$ of phosphate buffer, $\mathrm{pH} 7.4$; Sigma) were used. The animals were anesthetized with Nembutal $(50 \mathrm{mg} / \mathrm{kg}$, i.p.) and placed in a Kopf 900 stereotaxic instrument with blunt ear bars. The skin was retracted, a hole was drilled in the skull, and a $1 \mu \mathrm{l}$ Hamilton 7002 syringe filled with either NMDA $(n=20)$ or kainic acid $(n=10)$ solution was lowered into the medial septum using the following coordinates relative to bregma: $+0.6 \mathrm{~mm} \mathrm{AP,} 0.0 \mathrm{~mm} \mathrm{ML}$, and $-6.9 \mathrm{~mm}$ DV. Five minutes later, $150 \mathrm{nl}$ of NMDA or $200 \mathrm{nl}$ of kainic acid solution were infused at a rate of $100 \mathrm{nl} / 2 \mathrm{~min}$. After the infusion, the syringe remained in the brain for $10 \mathrm{~min}$. For the control animals $(n=15)$, an equivalent amount of phosphate buffer was infused into the medial septum using the procedures described above. The animals were kept warm, using a heating lamp, during and after the operation until they came out of anesthesia.

Intramedial septum cannula implantation. In 50 animals, a guide cannula (22 gauge, $11 \mathrm{~mm}$ length; Plastic Products Co., Roanoke, VA) was implanted into the medial septum, following the procedure described above. The coordinates with respect to bregma were $+0.2 \mathrm{~mm} \mathrm{AP,} 0.0$ $\mathrm{mm} \mathrm{ML}$, and $-6.3 \mathrm{~mm} \mathrm{DV}$.

Knife cut of the fimbria and electrolytic lesions of anterior commissure and dorsal hippocampus. To transect the fimbria, a knife was constructed using a commercial razor blade (catalog \#55411-050; VWR Scientifics, Media, PA). A razor blade was cut into a 1-mm-wide, 20-mm-long, rectangular shape, and all sides of the knife were sharpened on a fine grinding wheel. The knife was perpendicularly attached to a electrode carrier of a Kopf 900 stereotaxic instrument. Rats were anesthetized with Nembutal $(50 \mathrm{mg} / \mathrm{kg}$, i.p.) and placed in a Kopf stereotaxic instrument with blunt ear bars. The skin was retracted, and mediolaterally positioned 
2.4-mm-wide slits were cut bilaterally into the skull. To avoid damage to the sagital sinus, the area immediately lateral to the midline $( \pm 1 \mathrm{~mm}$ ML) was not touched. The coordinates with respect to bregma were -1.8 $\mathrm{mm}$ AP, between \pm 1 and $\pm 3.4 \mathrm{~mm} \mathrm{ML}$, and $-6.0 \mathrm{~mm}$ DV. In 10 animals, the knife was lowered into the brain, and a fimbria transection was made by moving the knife mediolaterally 20 times.

Following the procedure described previously, the dorsal hippocampus was lesioned in 10 animals. The lesion coordinates with respect to bregma were $-2.8 \mathrm{~mm} \mathrm{AP,} \pm 2.00 \mathrm{~mm} \mathrm{ML}$, and $-4.00 \mathrm{~mm} \mathrm{DV}$ and -4.3 $\mathrm{mm}$ AP, \pm 2.00 and $\pm 4.4 \mathrm{~mm} \mathrm{ML}$, and $-4.00 \mathrm{~mm} \mathrm{DV}$. DC current at 0.1 $\mathrm{mA}$ was delivered for $30 \mathrm{sec}$ at each of six lesion sites. To control for some possible nonspecific effects of the fimbria/fornix transection or lesions of the dorsal hippocampus, electrolytic lesions of another major fiber bundle in the vicinity of the medial septum, namely the anterior commissure, were used. The procedures for electrolytic lesions of the anterior commissure $(n=10)$ were the same as described above. The lesion coordinates with respect to bregma were $0.4 \mathrm{~mm} \mathrm{AP,} 0.00 \mathrm{~mm}$ ML, and $-7.5 \mathrm{~mm} \mathrm{DV}$, and the lesions were made using $0.1 \mathrm{~mA} \mathrm{DC}$ current for $30 \mathrm{sec}$.

Intracerebroventricular cannula implantation. Immediately after receiving lesions of the septal areas, dorsal hippocampus, or anterior commissure or fimbria transections, the animals were implanted with intracerebroventricular cannulas. A hole was drilled in the skull, and a unilateral guide cannula (22 gauge, $9 \mathrm{~mm}$ length; Plastic Products) fitted with a 28 gauge internal cannula (Plastic Products) extending $1.0 \mathrm{~mm}$ beyond the guide tip was lowered into the lateral ventricle (the laterality was balanced within a group). The coordinates with respect to bregma were 0.0 $\mathrm{mm}$ AP, $\pm 1.2 \mathrm{~mm} \mathrm{ML}$, and $-4.5 \mathrm{~mm}$ DV. The implanted cannulas were held in place using 0-80 jeweler's screws secured to the top of the skull and a crown of dental acrylic. The patency of the cannulas was maintained by inserting a stylet extending $1.0 \mathrm{~mm}$ beyond the guide cannula tip, secured with a dust cap throughout the recovery and testing periods.

\section{Test procedure and drug administration}

Postsurgery matching. Two weeks after surgery, the animals were tested with a matching procedure identical to that used for presurgery matching. The decision regarding which animals would be infused with CRH on test 1 and which would be infused with artificial CSF (ACSF) was made so that the mean startle amplitudes across the last 10 trials in the postmatching test were equivalent in the $\mathrm{CRH}$ and vehicle groups.

Intracerebroventricular CRH test. The effect of intracerebroventricular $\mathrm{CRH}$ on startle was tested $1 \mathrm{~d}$ after postsurgery matching. The animals were given a predrug baseline test, which was identical to the matching test. Immediately after the test, the animals were removed from the cage, and half were infused with CRH $(1 \mu \mathrm{g} / 5 \mu \mathrm{l}$, human/rat CRH; Peninsula Laboratory), whereas the other half were inf used with the vehicle, ACSF $(5 \mu \mathrm{l})$. Infusions were made using a 28 gauge internal cannula (Plastic Products) connected to a $10 \mu \mathrm{l}$ Hamilton microsyringe mounted on a Harvard 975 infusion pump. The flow rate was $2.5 \mu \mathrm{l} / 1$ min. After infusion, the internal cannula remained inside of the lateral ventricle for another $1 \mathrm{~min}$. After intracerebroventricular infusion, the animals were placed back in the startle chambers and presented with 240 startleeliciting noise bursts at a $30 \mathrm{sec}$ ITI (post-drug test). The entire post-drug test duration was $120 \mathrm{~min}$. Forty-eight hours later, the animals were tested again using a crossover design in which the animals inf used with $\mathrm{CRH}$ on test 1 were infused with ACSF on test 2 and vice versa.

Intramedial septal injection of $C R H$. One week after surgery, the animals received a postsurgery matching test as described above, and the animals were divided into four groups, having similar mean startle amplitudes across the last 10 startle stimuli. One day later, the animals were placed in the startle cages and given a predrug baseline test, identical to the matching tests. Immediately thereafter, the animals were removed from the cages and inf used with one of three doses of CRH (7.5, 30 , or $120 \mathrm{ng} / 0.5 \mu \mathrm{l}$ ) or ACSF into the medial septum over $2 \mathrm{~min}$. After infusion, the internal cannula remained in the brain for another $1 \mathrm{~min}$. The animals were then placed back into the startle chambers and presented with 120 noise bursts at a $30 \mathrm{sec}$ ITI (after the drug test). The entire intramedial septum post-drug test session was 60 min long.

\section{Histology}

At the completion of the studies, the animals were deeply anesthetized with chloral hydrate $(800 \mathrm{mg} / \mathrm{kg}$, i.p. $)$ and perfused intracardially with saline followed by $10 \%$ formalin. Brains were removed and fixed in $30 \%$ sucrose in $10 \%$ formalin solution. Coronal sections $(40 \mu \mathrm{m})$ were cut through the relevant brain areas, and every third section was mounted

\begin{tabular}{lcc}
\hline \multicolumn{2}{l}{ Table 1. Predrug baseline startle scores } & \\
& Pre-ACSF & Pre-CRH \\
\hline Electrolytic lesion & & \\
$\quad$ Lateral septum & $224 \pm 54$ & $194 \pm 52$ \\
$\quad$ Medial septum & $216 \pm 29$ & $255 \pm 38$ \\
Septum & $250 \pm 48$ & $315 \pm 63$ \\
Sham & $155 \pm 16$ & $182 \pm 22$ \\
& & $F_{(3,39)}=0.37, p<0.775$ \\
Chemical lesion & & $307 \pm 44$ \\
Medial septum & $244 \pm 33$ & $237 \pm 34$ \\
Sham & $231 \pm 40$ & $F_{(1,27)}=0.02 ; p<0.879$ \\
& & \\
Intramuscular infusion & & \\
ACSF & $258 \pm 26$ & $230 \pm 44$ \\
7.5 ng & & $223 \pm 33$ \\
30 ng & & $309 \pm 51$ \\
120 ng & & $F_{(3,43)}=0.96 ; p<0.422$ \\
& & $282 \pm 40$ \\
Transection and lesion & & $213 \pm 35$ \\
Fimbria & $318 \pm 77$ & $208 \pm 34$ \\
Anterior commissure & $208 \pm 33$ & $F_{(2,20)}=0.59 ; p<0.561$ \\
Dorsal hippocampus & $275 \pm 52$ & \\
& &
\end{tabular}

onto gelatin-coated slides. For verification of the electrolytic lesions of the septum and the anterior commissure, and both intracerebroventricular cannulation and the intramedial septum cannulation, the sections were stained with cresyl violet. NMDA lesions and kainic acid lesions of the medial septum and fimbria transections were verified using the Kluver-Barrera method to assess damage to cell bodies versus fibers of passage.

\section{Data analysis}

A predrug startle score was computed by taking the mean of the last 10 startle amplitudes of the predrug test. For each animal, the post-drug startle test scores were blocked by 20 ( 12 blocks), with the mean startle amplitude of each block designated as the raw startle score.

Table 1 shows the predrug baseline startle scores of the various groups in the test sessions over the four different experiments, along with the overall ANOVAs on these baseline scores. A separate ANOVA on the predrug baseline for each experiment revealed no significant differences in baseline startle scores of the various groups over test days. Therefore, the mean percent change scores will be used for graphic presentation of data.

Percent change scores were derived by subtracting the baseline scores from each raw startle score after infusion. These difference scores were then divided by the baseline scores and multiplied by 100 [(post pre)/pre $\times 100]$. For statistical evaluations of the drug effects after electrolytic or chemical lesions, the predrug baseline and the mean startle amplitude over the last 120 trials after CRH infusion (last $60 \mathrm{~min}$, trials 121-240) were calculated. These were compared with baseline and mean startle amplitude after ACSF infusion using a repeated measures ANOVA. For statistical evaluation of the effects of intramedial septum $\mathrm{CRH}$ infusion on startle, each animal's predrug baseline and its mean startle amplitude over the first 60 or 20 trials after CRH infusion (first 30 or $10 \mathrm{~min}$ ) was calculated and compared using a repeated measures ANOVA.

\section{RESULTS}

\section{Effects of electrolytic lesions of the septal areas on CRH-enhanced startle}

Histological verification of the lateral septal lesions was extremely difficult because of the gross enlargement of the lateral ventricles, which severely compressed the lateral septal area. Although it was suspected that the enlargement of the ventricle probably resulted 
$\mathbf{A}$

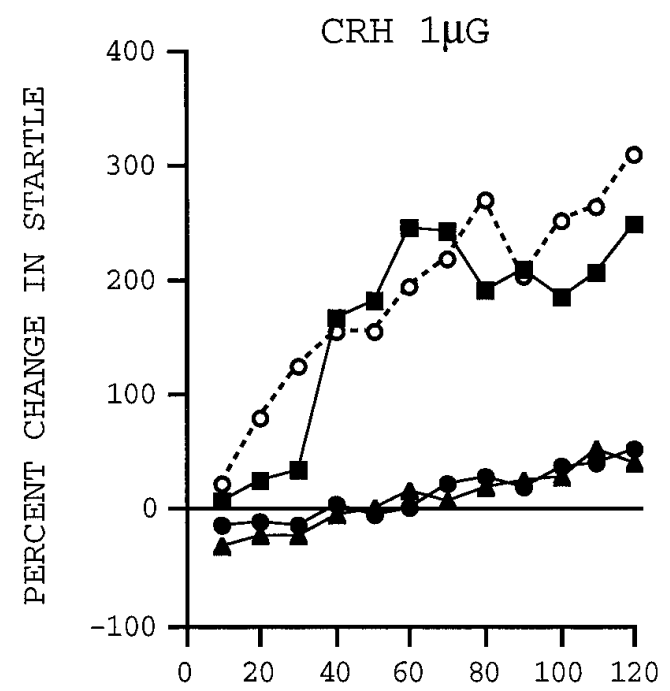

B

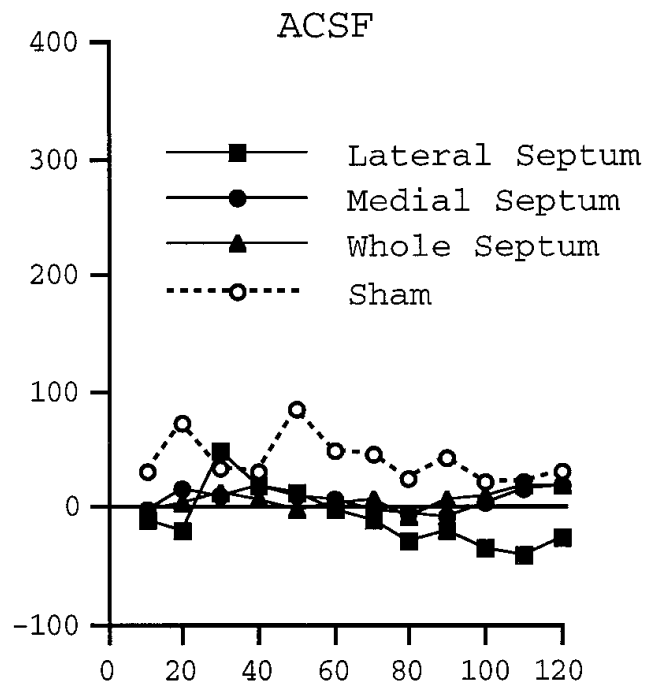

MINUTES AFTER INFUSION

C Lat. septum

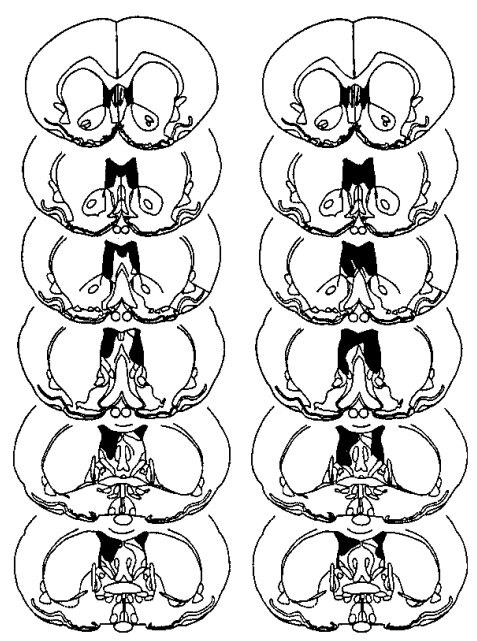

Med. septum

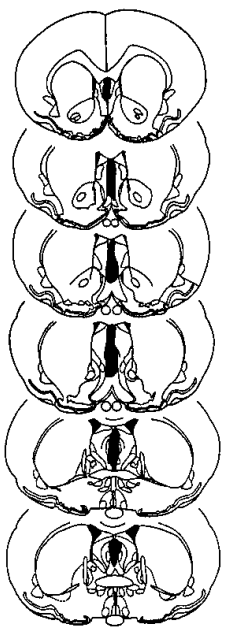

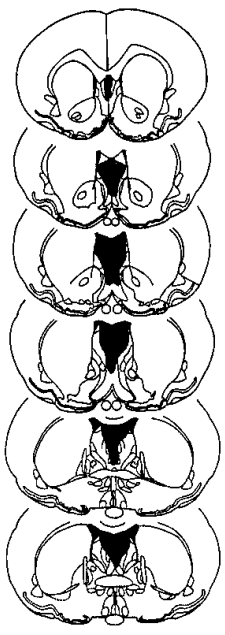

Septum
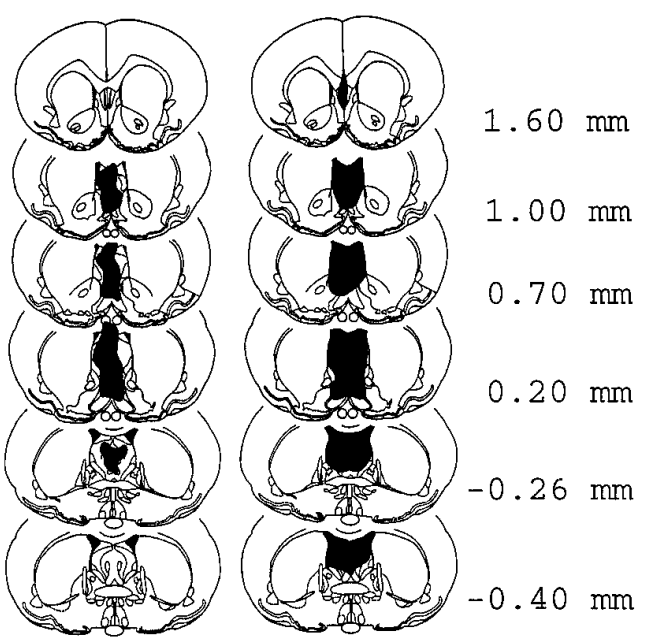

Figure 1. Effects of sham or electrolytic lesions of the lateral, medial, or whole septum on mean percent change of startle amplitude after intracerebroventricular infusion of $1 \mu \mathrm{g}$ of CRH $(A)$ or ACSF $(B)$. Each data point represents the mean percent change of 20 post-drug test trials. $C$, Largest (right) and smallest (left) lesions of these areas.

from lesions of the lateral septum, behavioral data from 11 animals in which it was not possible to verify the extent of the lesions were excluded. Three of the remaining nine animals showed partial lesions of the lateral septum, and two other animals showed unusually low baseline startle amplitudes $(<70$ units); therefore, they were excluded from the statistical data analysis. However, inspection of the data from these excluded rats showed that their results were essentially identical to the animals included in the formal data analysis. Two of the 20 medial septum-lesioned animals had partial lesions, and two other medial septum-lesioned animals had intracerebroventricular cannula misplacement and were thus eliminated from data analysis. Interestingly, the whole septum lesions caused less severe ventricle enlargement, and all 15 animals were included. Two control animals were excluded because of intracerebroventricular cannula misplacement or low startle baselines ( $<70$ units).

This resulted in the following group sizes: lateral septum, $n=$ 4; medial septum, $n=16$; whole septum, $n=15$; and sham, $n=$ 8 . Figure $1 C$ illustrates histological reconstructions of the largest and smallest electrolytic lesions of the lateral septum, medial septum, and whole septum.

As summarized in Figure $1 A$, electrolytic lesions of the whole septum and medial septum completely blocked CRH-enhanced startle, whereas electrolytic lesions of the lateral septum failed to do so. Intracerebroventricular infusion of ACSF did not increase startle amplitudes in any of the four groups (Fig. 1B). Consistent 
A

$$
\begin{gathered}
\text { Chemical lesions of } \\
\text { the medial septum }
\end{gathered}
$$

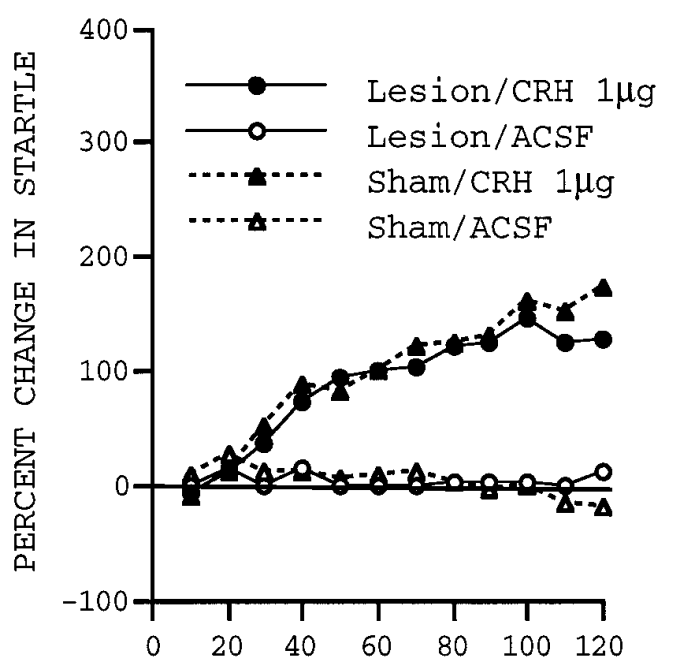

MINUTES AFTER INFUSION
B

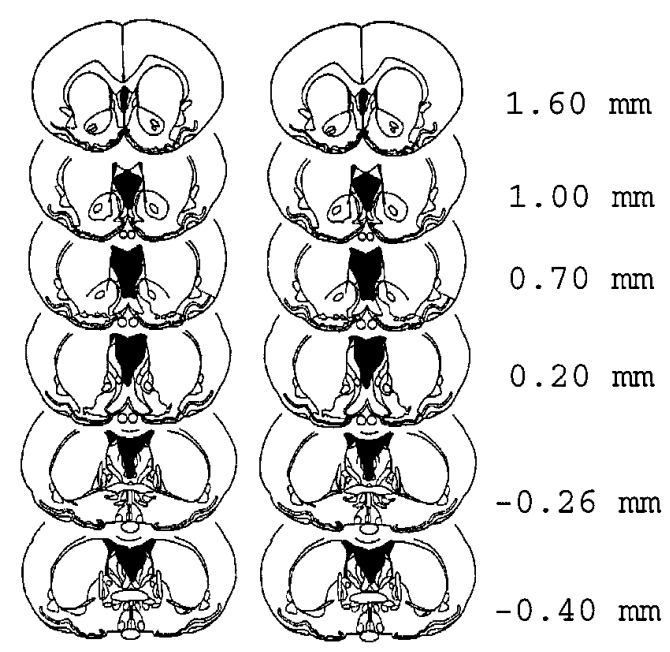

Figure 2. A, Effects of chemical lesions of the medial septum on mean percent change of startle amplitude after intracerebroventricular inf usion of 1 $\mu \mathrm{g}$ of CRH or ACSF. Each data point represents the mean percent change of 20 post-drug test trials. B, Largest (right) and smallest (left) lesions of the medial septum.

with this conclusion, an overall ANOVA showed that there was no significant lesion effect $\left(F_{(3,39)}=0.52 ; p<0.674\right)$, whereas the main drug effect (CRH vs ACSF, $\left.F_{(1,39)}=29.29 ; p<0.001\right)$ and the main time effect (predrug baseline vs postdrug) were statistically significant $\left(F_{(1,39)}=47.01 ; p<0.001\right)$. More importantly, the three-way interaction (lesion $\times$ drug $\times$ time) was statistically significant $\left(F_{(3,39)}=14.47 ; p<0.001\right)$, indicating that the magnitude of CRH-enhanced startle differed after various lesions. Post hoc analyses, using Tukey's multiple comparisons, revealed that the medial septum-lesioned as well as the whole septumlesioned animals showed significantly smaller CRH-enhanced startle compared with that of the sham-lesioned animals $(p<$ 0.001 in each case). Furthermore, there was no statistical difference in the magnitude of blockade of CRH effects after medial septum lesions and whole septum lesions $(p<0.923)$.

Electrolytic lesions of the whole septum, as well as the medial septum, completely blocked CRH-enhanced startle. The pattern and magnitude of blockade induced by medial septal lesions were almost identical to those seen after the whole septum lesions, suggesting that the effect of the whole septum lesions resulted from the lesions of the medial septum. In contrast, electrolytic lesions of the lateral septum did not have an effect on CRHenhanced startle. This failure was not likely caused by incomplete lesions of the lateral septum. Thus, although electrolytic lesions of the lateral septum induced profound enlargement of the lateral ventricles, which made the histological verification of the lesion sites technically very difficult, animals with partial lesions $(n=14$; data not shown) as well as those with verifiable, complete lesions of the lateral septum $(n=4)$ failed to block CRH-enhanced startle.

It is known that lesions of the septal area increase startle amplitude, although this excitatory effect dissipates over 10-14 d (Brady and Nauta, 1953). In the present study, all the behavioral tests were performed after a $14 \mathrm{~d}$ recovery period after septal lesions, to minimize possible excitatory effects of the septal lesions independent of intracerebroventricular CRH effects on startle. Although the baseline startle amplitudes of the lesioned animals were slightly higher than those of sham-lesioned animals, even after the $14 \mathrm{~d}$ recovery period, the difference was not statistically significant (see Table 1). Therefore, it is unlikely that the results of the present experiment were confounded with nonspecific interactions between $\mathrm{CRH}$ and residual effects of the septal lesions on baseline startle amplitudes.

\section{Effects of chemical lesions of the medial septum on CRH-enhanced startle}

Fourteen of the 20 NMDA-lesioned animals had either incomplete lesions of the medial septum $(n=11)$, cannula misplacements $(n=2)$, or death $(n=1)$ and were excluded from further analysis. Four of 10 kainic acid-lesioned animals showed complete lesions of the medial septum. Six lesioned animals were excluded because of incomplete lesions $(n=2)$, death $(n=3)$, or cannula misplacement $(n=1)$. One of the sham-lesioned animals was also excluded from data analysis because of cannula misplacement. This left the following sample sizes: NMDA lesion, $n=6$; kainic acid lesion, $n=4$; and sham, $n=14$. Behavioral data of kainic acid-lesioned animals were indistinguishable from those of NMDA-lesioned animals, so their data were combined for further analysis. Figure $2 B$ shows representative lesions of the medial septum after chemical lesions.

Surprisingly, complete chemical lesions of the medial septum using kainic acid or NMDA failed to block CRH-enhanced startle (Fig. $2 A$ ). Although there was a highly significant main drug effect $\left(F_{(1,27)}=43.23 ; p<0.001\right)$, indicating an overall excitatory effect of CRH on startle, there was no significant drug by lesion interaction $(p<0.310)$, nor drug by time by group interaction $(p<$ 
0.792). An overall ANOVA showed neither a significant main lesion effect $(p<0.276)$ nor a significant time by lesion interaction $(p<0.536)$.

The most parsimonious interpretation of the present data is that the blockade of $\mathrm{CRH}$-enhanced startle in experiment 1 resulted from damage to fibers of passage, presumably the fornix. Although it is unlikely, an alternative interpretation is that the subset of cells critical for mediating $\mathrm{CRH}$-enhanced startle was not sensitive to either kainic acid or NMDA. There was some sparing of cells $(<10 \%)$ in the most caudal part of the medial septum after the chemical lesions. Hence it is still possible that this part of the septum is critical for CRH-enhanced startle.

\section{Effects of intramedial septum infusion of CRH on startle}

One ACSF group animal and two $30 \mathrm{ng}$ animals were excluded from data analysis because of cannula misplacement. Figure $3 B$ shows composites of the cannula placements of the four groups, and Figure $3 C$ shows a photomicrograph illustrating a representative cannula placement.

As shown in Figure $3 A$, intramedial septum infusion of $\mathrm{CRH}$ seemed to have a very short-lasting, marginal excitatory effect on startle, especially at the $30 \mathrm{ng}$ dose. Although the onset of the intramedial septum $\mathrm{CRH}$ effect was immediate, compared with the profound and long-lasting intracerebroventricular CRH effect, the effect was weak and transient. An ANOVA showed no significant dose effect over the first 30 min after infusion of the various doses of CRH into the medial septum $\left(F_{(3,42)}=0.76 ; p<\right.$ 0.525). An ANOVA using the mean startle amplitude over the first 10 min after infusion did reveal a significant dose effect $\left(F_{(3,42)}=3.08 ; p<0.038\right)$. However, the group by time interaction was not significant $(p<0.093)$, indicating no significant dose-dependent change in startle amplitude after intramedial septum infusion of CRH. The transient and non-dose-dependent nature of $\mathrm{CRH}$ effects after intramedial septum infusion makes it unlikely that the medial septum is the location where intracerebroventricular $\mathrm{CRH}$ exerts its long-lasting and profound excitatory effect on startle.

\section{Effects of the fimbria transection and electrolytic lesions of the dorsal hippocampus and anterior commissure on CRH-enhanced startle}

The failure of intramedial septal $\mathrm{CRH}$ to enhance startle in a manner comparable to intracerebroventricular CRH suggested that the medial septum per se is probably not involved in CRHenhanced startle, and that the blockade seen after electrolytic lesions of the medial septum probably resulted from damage of fibers passing through the septum. A major fiber bundle passing through the medial septum is the fornix (Raisman, 1969; Kiss et al., 1990; Jakab and Leranth, 1995), therefore, in the following experiment, the role of the fimbria/fornix and one of its efferent structures, the dorsal hippocampus, in CRH-enhanced startle was investigated.

Three of 10 fimbria transection animals were excluded from data analysis because of incomplete transections $(n=2)$ or intracerebroventricular cannula misplacement $(n=1)$. Three of 10 dorsal hippocampus animals were also excluded from data analysis because of a low baseline $(n=1)$, damage to the fimbria $(n=1)$, or death $(n=1)$. One of 10 anterior commissure-lesioned animals was excluded from data analysis because of cannula misplacement. The first two panels of Figure $4 C$ show representative lesions of the dorsal hippocampus and anterior commis- sure. The photomicrograph in Figure 5 illustrates a representative transection of the fimbria/fornix.

Figure $4 A$ shows that complete transection of the fimbria/ fornix eliminated the excitatory effect of intracerebroventricular $\mathrm{CRH}$ on startle. However, this blockade did not seem to result from damage to the efferent fibers from the dorsal hippocampus, because electrolytic lesions of the dorsal hippocampus did not block CRH-enhanced startle. Furthermore, the blockade of $\mathrm{CRH}$-enhanced startle seemed not to be caused by nonspecific effects of surgery, because electrolytic lesions of yet another fiber bundle, the anterior commissure, had no effect on CRHenhanced startle. Infusion of ACSF had no effect in all three groups (Fig. 4B).

Supporting this conclusion, an overall ANOVA showed a significant main effect of drug $\left(\mathrm{CRH}\right.$ vs $\mathrm{ACSF}, F_{(1,20)}=10.12 ; p<$ $0.005)$ and drug by group interaction $\left(F_{(2,20)}=3.40 ; p<0.054\right)$. More importantly, the time (predrug vs postdrug) by drug by group interaction was also significant $\left(F_{(2,20)}=4.56 ; p<0.023\right)$, indicating that the magnitude of $\mathrm{CRH}$-enhanced startle was different between groups. A post hoc test, using Tukey's multiple comparisons, revealed that the magnitude of $\mathrm{CRH}$-enhanced startle was significantly lower in the fimbria/fornix transection group compared with either the anterior commissure lesion group $(p<0.036)$ or the dorsal hippocampus lesion group $(p<0.046)$. Taken together, these results, although indirect, strongly suggest that the blockade of CRH-enhanced startle seen after electrolytic lesions of the medial septum was caused by the lesions of the fornix.

\section{DISCUSSION}

The present studies examined the hypothesis that intracerebroventricular $\mathrm{CRH}$ increases startle amplitude by inhibiting the lateral septum, which in turn disinhibits the amygdala. Contrary to expectation, electrolytic lesions of the lateral septum did not block CRH-enhanced startle, whereas electrolytic lesions of the whole septum and the medial septum completely blocked CRHenhanced startle. However, fiber-sparing chemical lesions of the medial septum failed to block CRH-enhanced startle, suggesting that the blockade seen with electrolytic lesions of the medial septum was likely caused by damage to fibers passing through this area. Although most of the medial septum was destroyed after chemical lesions, a small number of cells in the caudal part of the medial septum were spared, leaving the possibility that these cells are critical for $\mathrm{CRH}$-enhanced startle. However, direct infusion of CRH into this area failed to mimic the intracerebroventricular $\mathrm{CRH}$ effect on startle, producing only a small, transient, and non-dose-related increase in startle amplitude. Compared with the profound and long-lasting excitatory effects of CRH on startle after intracerebroventricular administration, this effect of intramedial septum CRH suggests that the medial septum is not the primary receptor site for $\mathrm{CRH}$ given intracerebroventricularly. Taken together, the results from this microinfusion study support the conclusion that the blockade seen with electrolytic lesions of the medial septum probably resulted from damage to fibers passing through the medial septum.

A major fiber bundle passing through the medial septum is the fornix (Raisman, 1969; Kiss et al., 1990; Jakab and Leranth, 1995). The results from the first three experiments suggested that the functional integrity of the fornix is necessary for CRHenhanced startle. Therefore, the role of the fornix in $\mathrm{CRH}$ enhanced startle was examined using transection of the fimbria. The fimbria is a massive fiber bundle that eventually funnels in to 
A

Intra-medial septum $\mathrm{CRH}$

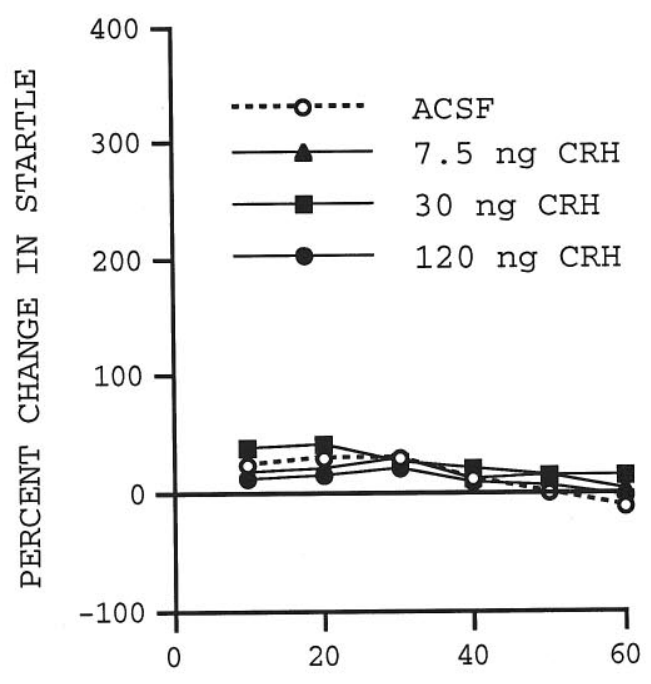

MINUTES AFTER INFUSION

B
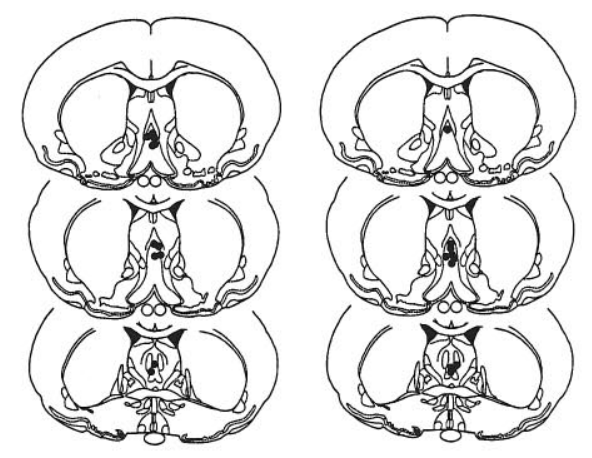

C

$7.5 \mathrm{ng}$

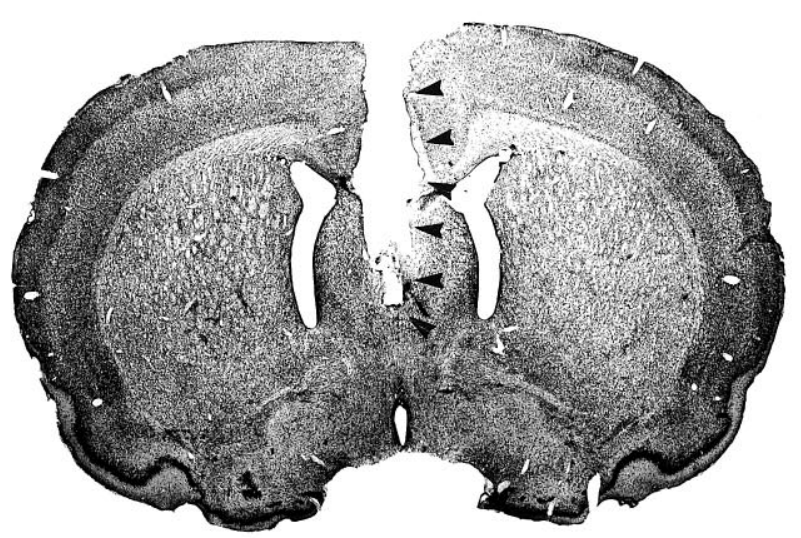

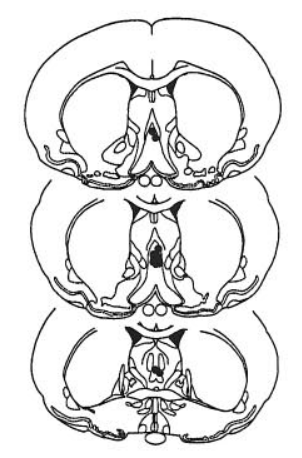

$30 \mathrm{ng}$

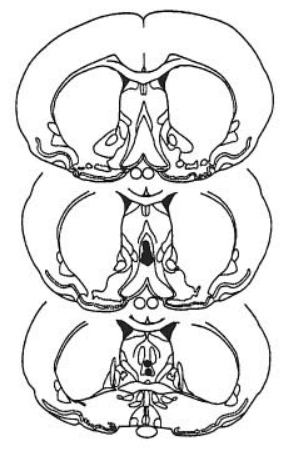

$0.70 \mathrm{~mm}$

$0.20 \mathrm{~mm}$

$-0.26 \mathrm{~mm}$

Figure 3. $A$, Effects of various doses of $\mathrm{CRH}$ infused into the medial septum on mean percent change of startle amplitude. Each data point represents the mean percent change of 20 post-drug test trials. $B$, Histological reconstructions showing placement of cannula tips of the animals included in the data analysis. $C$, Photomicrograph illustrating a representative cannula placement in the medial septum. The black arrowheads point to the cannula track. 
A

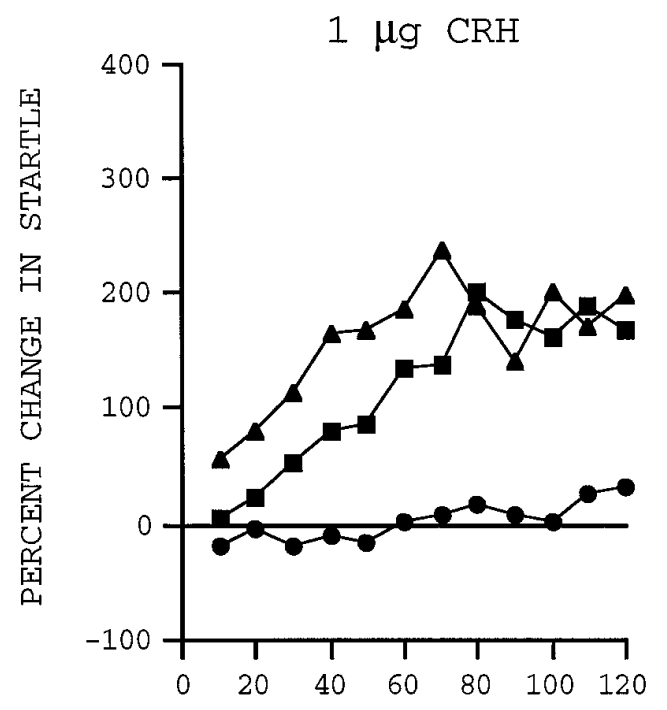

B

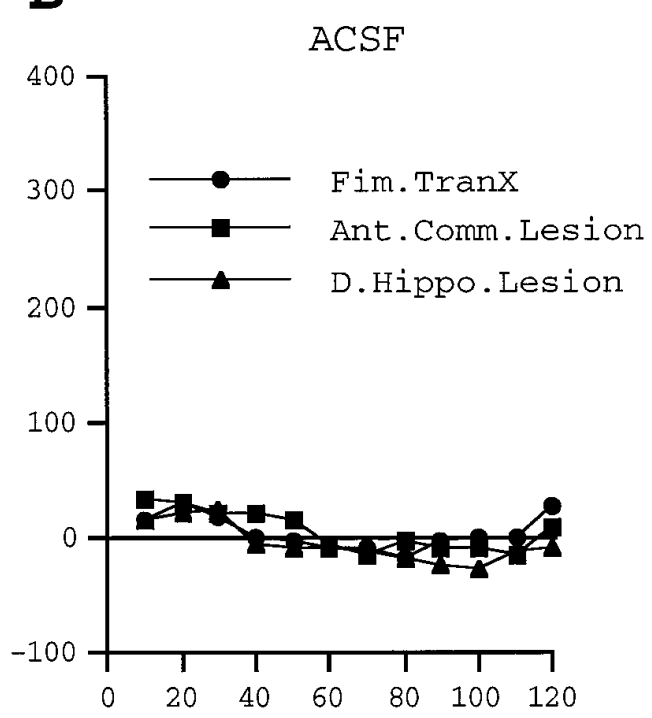

MINUTES AFTER INFUSION

C

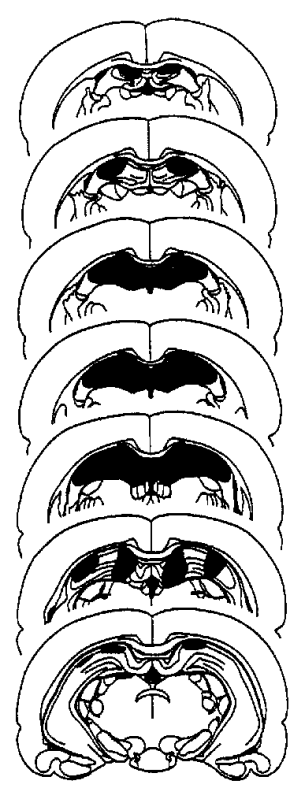

D. Hippocampus

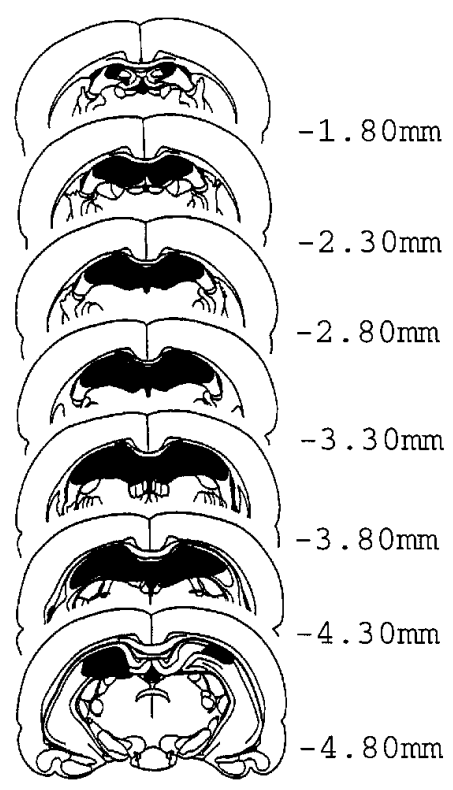

Ant. Commissure

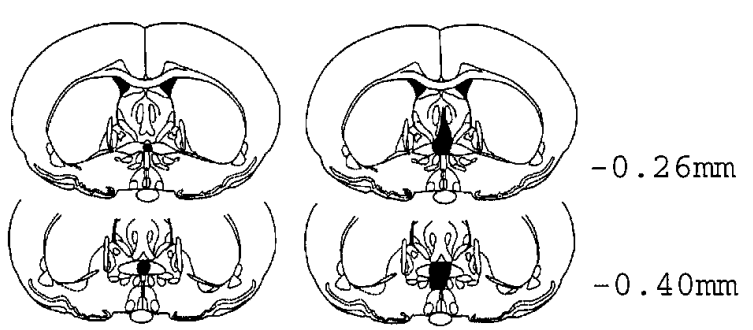

Figure 4. $A, B$, Effects of fimbria transection and electrolytic lesions of the dorsal hippocampus and anterior commissure on mean percent change of startle amplitude after intracerebroventricular infusion of $1 \mu \mathrm{g}$ of CRH $(A)$ or ACSF $(B)$. Each data point represents the mean percent change of 20 post-drug test trials. $C$, Largest (right) and smallest (left) electrolytic lesions of the dorsal hippocampus and anterior commissure.

form the fornix, so that the fimbria and fornix are considered functionally as a single unit (cf. Amaral and Witter, 1995). As expected, transection of the fimbria completely blocked CRHenhanced startle, suggesting that the blockade of CRH-enhanced startle after electrolytic lesions of the medial septum was caused by damage to the fornix.

The blockade of CRH-enhanced startle by transection of the fimbria also suggests that structures communicating via the fimbria/fornix might be critically involved in CRH-enhanced startle.
The fimbria/fornix is the main output pathway for the hippocampus (cf. Amaral and Witter, 1995). Therefore, it is possible that the hippocampus, which contains a moderate number of $\mathrm{CRH}$ receptors (De Souza et al., 1984; Chalmers et al., 1995), is a primary receptor site for intracerebroventricular $\mathrm{CRH}$, and fimbria transection blocked $\mathrm{CRH}$-enhanced startle because it destroyed efferent fibers of the hippocampus essential for modulating the startle reflex. Among the subdivisions of the hippocampus, we were particularly interested in the dorsal hip- 


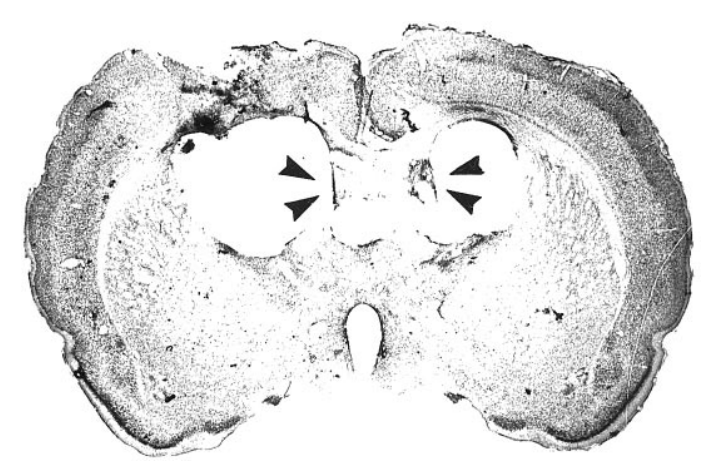

Figure 5. Photomicrograph showing a representative fimbria transection. The black arrowheads point to the transected areas.

pocampus, because others have reported that the dorsal hippocampus is involved in mediating locomotor-stimulating effects of CRH (Lee and Tsai, 1989). Furthermore, CRH systems in the dorsal hippocampus are also known to be involved in consolidation and retention of aversive memory in rats (Hung et al., 1992; Lee et al., 1992). The dorsal hippocampus, however, does not seem to play a critical role in CRH-enhanced startle, because electrolytic lesions of this area did not block CRH-enhanced startle.

In a recent study, Cullinan et al. (1993) showed that the ventral hippocampus projects to the bed nucleus of the stria terminalis (BNST) mainly through the fimbria/fornix. Therefore, the ventral hippocampus and/or the BNST could be possible receptor areas for CRH given intracerebroventricularly. For example, the binding of $\mathrm{CRH}$ to ventral hippocampal $\mathrm{CRH}$ receptors could modulate startle via projections through the fornix to areas such as the BNST, which is known to project to the startle pathway directly, or indirectly via the amygdala (Y. Lee, C. Shi, and M. Davis, unpublished observation). Alternatively, the BNST might be a primary receptor site for $\mathrm{CRH}$ given intracerebroventricularly, with the ventral hippocampus playing a permissive role for the BNST to express CRH-enhanced startle. A recent study demonstrating that lesions of the hippocampus prevented certain types of cells in the nucleus accumbens to shift from a quiescent mode to a burst-firing mode supports the notion that the hippocampus may play a permissive role in activation of certain brain areas (O’Donnell and Grace, 1996). Yet another possibility is that intracerebroventricular $\mathrm{CRH}$ activates both the ventral hippocampus and the BNST, and that the summation of excitation from these two areas is essential to elicit the full excitatory effect on startle seen after intracerebroventricular administration of CRH. In fact, in our companion paper in this issue (Lee and Davis, 1997), we have data to suggest that the BNST is a primary receptor site for $\mathrm{CRH}$ given intracerebroventricularly.

\section{REFERENCES}

Amaral DG, Witter MP (1995) Hippocampal formation. In: The rat nervous system (Paxinos G, ed), pp 443-493. San Diego: Academic.

Arnold FJL, De Lucas Bueno M, Shiers H, Hancock DC, Evan G, Herbert J (1992) Expression of c-fos in regions of the basal limbic forebrain following intracerebroventricular corticotropin-releasing factor in unstressed or stressed male rats. Neuroscience 51:377-390.

Brady JH, Nauta WJH (1953) Subcortical mechanisms in emotional behavior: affective changes following septal forebrain lesions in the albino rat. J Comp Physiol Psychol 46:339-346.

Chalmers D, Lovenberg TW, De Souza EB (1995) Localization of novel corticotropin-releasing factor receptor (CRF2) mRNA expression to specific subcortical nuclei in rat brain: comparison with CRF1 Receptor mRNA expression. J Neurosci 15:6340-6350.
Cullinan WE, Herman JP, Watson SJ (1993) Ventral subicular interaction with the hypothalamic paraventricular nucleus: evidence for a relay in the bed nucleus of the stria terminalis. J Comp Neurol 332:1-20.

Darnell A, Bremer JD, Licino J, Krystal J, Nemeroff CB, Owens M, Erdos J, Charney DS (1994) CSF levels of corticotropin releasing factor I chronic post-traumatic stress disorder. Soc Neurosci Abstr 20:17.

Davis M (1984) The mammalian startle response. In: Neural mechanisms of startle behavior (Eaton RC, ed), pp 287-351. New York: Plenum.

Davis M (1988) The potentiated startle response as a measure of conditioned fear and its relevance to the neurobiology of anxiety. In: Animal models of psychiatric disorders (Simon P, Soubrie P, eds), pp 61-89. Paris: Wildlocher.

Davis M, Gendelman DS, Tischler MD, Gendelman PM (1982) A primary acoustic startle circuit: lesion and stimulation studies. J Neurosci 2:791-805.

De Souza EB, Perrin MH, Insel TR, Rivier JE, Vale WW, Kuhar MJ (1984) Corticotropin-releasing factor receptors in rat forebrain: autoradiographic identification. Science 224:1449-1451.

Dudley CA, Lee Y, Moss R (1990) Electrophysiological identification of pathway from the septal area to the medial amygdala: sensitivity to estrogen and luteinizing hormone releasing hormone. Synapse 6:161-168.

Dunn AJ, Berridge CW (1990) Physiological and behavioral responses to corticotropin-releasing factor administration: is CRF a mediator of anxiety or stress responses? Brain Res Rev 15:71-100.

Eberly LB, Dudlely CA, Moss RL (1983) Iontophoretic mapping of corticotropin-releasing factor (CRF) sensitive neurons in the rat forebrain. Peptides 4:837-841.

Hung HC, Chou CK, Chiu TH, Lee EH (1992) CRF increases protein phosphorylation and enhances retention performance in rats. NeuroReport 3:181-184.

Imaki T, Shibasaki T, Hotta M, Demura H (1993) Intracerebroventricular administration of corticotropin-releasing factor induces c-fos mRNA expression in brain regions related to stress responses: comparison with pattern of c-fos mRNA induction after stress. Brain Res 616:114-125.

Jakab RL, Leranth C (1995) Septum. In: The rat nervous system (Paxinos G, ed), pp 405-442. San Diego: Academic.

King FA, Meyer PM (1958) Effects of amygdaloid lesions upon septal hyperemotionality in the rat. Science 128:655-656.

Kiss J, Patel AJ, Freund TF (1990) Distribution of septohippocampal neurons containing parvalbumin or choline acetyltransferase in the rat brain. J Comp Neurol 298:362-372.

Kleiner FB, Meyer PM, Meyer DR (1967) Effects of simultaneous septal and amygdala lesions upon emotionality and retention of a black-white discrimination. Brain Res 5:459-468.

Lee EH, Tsai MJ (1989) The hippocampus and amygdala mediate the locomotor stimulating effects of corticotropin-releasing factor in mice. Behav Neural Biol 51:412-423.

Lee EH, Hung HC, Lu KT, Chen WH, Chen HY (1992) Protein synthesis in the hippocampus associated with memory facilitation by corticotropin-releasing factor in rats. Peptides 13:927-937.

Lee EHY, Lin YP, Yin TH (1988) Effects of lateral and medial septal lesions of various activity and reactivity measures in the rat. Physiol Behav 42:97-102.

Lee Y, Davis M (1997) Role of the hippocampus, the bed nucleus of the stria terminalis, and the amygdala in the excitatory effect of corticotropin-releasing hormone on the acoustic startle reflex. J Neurosci 17:6434-6446.

Lee Y, López DE, Meloni EG, Davis M (1996) A primary acoustic startle pathway: obligatory role of cochlear root neuron and the nucleus reticularis pontis caudalis. J Neurosci 16:3775-3789.

Liang KC, Melia KR, Miserendino MJD, Falls WA, Campeau S, Davis M (1992a) Corticotropin-releasing factor: long-lasting facilitation of the acoustic startle reflex. J Neurosci 12:2303-2312.

Liang KC, Melia KR, Campeau S, Falls WA, Miserendino MJD, Davis M (1992b) Lesions of the central nucleus of the amygdala, but not the paraventricular nucleus of the hypothalamus block the excitatory effects of corticotropin-releasing factor on the acoustic startle reflex. J Neurosci 12:2313-2320.

Lingenhöhl K, Friauf E (1994) Giant neurons in the rat reticular formation: a sensorimotor interface in the elementary acoustic startle circuit? J Neurosci 14:1176-1194.

Meibach R, Siegel A (1977) Efferent connections of the septal area in the 
rat: an analysis utilizing retrograde and anterograde transport methods. Brain Res 119:1-20.

Melia KR, Sananes CB, Davis M (1991) Lesions of the central nucleus of the amygdala block the excitatory effects of septal ablation on the acoustic startle reflex. Physiol Behav 51:175-180.

Miller SW, Treft RL (1979) Habituation of the acoustic startle response following lesion of the medial septal nucleus. Physiol Behav 23:645-648.

Moga MM, Herbert H, Hurley KM, Yasui Y, Gray TS, Saper CB (1991) Organization of cortical, basal forebrain, and hypothalamic afferents to the parabrachial nucleus in the rat. J Comp Neurol 295:624-661.

Morgan III CA, Grillon C, Southwick SM, Davis M, Charney DS (1995) Fear-potentiated startle in posttraumatic stress disorder. Biol Psychiatry 38:378-385.

O'Donnell P, Grace AA (1996) Synaptic interactions among excitatory afferents to nucleus accumbens neurons: hippocampal gating of prefrontal cortical input. J Neurosci 15:3622-3639.

Raisman G (1969) A comparison of the mode of termination of the hippocampal and hypothalamic afferents to the septal nuclei as revealed by electron microscopy of degeneration. Exp Brain Res 7:317-343.

Russchen FT (1982) Amygdalopetal projections in the cat. II Subcortical afferent connections. A study with retrograde tracing techniques. J Comp Neurol 207:157-176.

Sawchenko PE, Swanson LW (1983) The organization of forebrain af- ferents to the paraventricular and supraoptic nucleus of the rats. J Comp Neurol 218:121-144.

Schwartzbaum JS, Gay PE (1966) Interacting behavioral effects of septal and amygdaloid lesions in the rat. J Comp Physiol Psychol 61:59-65.

Silverman AJ, Hoffman DL, Zimmerman EA (1981) The descending afferent connections of the paraventricular nucleus of the hypothalamus (PVN). Brain Res Bull 6:47-61.

Staiger JF, Nürnberger F (1991) The efferent connections of the lateral septal nucleus in the guinea pig: projections to the diencephalon and brain stem. Cell Tissue Res 264:391-413.

Swanson L, Cowan WM (1979) The connections of the septal region in the rat. J Comp Neurol 186:621-656.

Swerdlow NR, Geyer MA, Vale WW, Koob GF (1986) Corticotropinreleasing factor potentiates acoustic startle in rats: blockade by chlordiazepoxide. Psychopharmacology (Berl) 88:147-152.

Swerdlow NR, Britton KT, Koob GF (1989) Potentiation of acoustic startle by corticotropin-releasing factor (CRF) and by fear are both reversed by $\alpha$-helical CRH (9-41). Neuropsychopharmacology 2:285-292.

Volz HP, Rehbein G, Triepel J, Kneupfer MM, Stumpf H, Stock G (1990) Afferent connections of the nucleus centralis amygdalae. Anat Embryol (Berl) 181:177-194.

Yeomans JS, Frankland PW (1995) The acoustic startle reflex: neurons and connections. Brain Res Rev 21:301-314. 